\section{Abstract}

\title{
Scour influence on the fatigue life of operational monopile-supported offshore wind turbines
}

\author{
Ramtin Rezaei $^{\mathrm{a}}$, Philippe Duffour ${ }^{\mathrm{a}}$, Paul Fromme ${ }^{\mathrm{b}}$ \\ ${ }^{a}$ Department of Civil, Environmental \& Geomatic Engineering, UCL, London, WC1E 6BT, UK \\ ${ }^{b}$ Department of Mechanical Engineering, UCL, London, WC1E 6BT, UK \\ Contact Author: p.duffour@ucl.ac.uk
}

Offshore wind turbines (OWTs) supported on monopiles are an important source for renewable energy. Their fatigue life is governed by the environmental loads and the dynamic behaviour, depending on the support stiffness and thus soil-structure interaction. The effects of scour on the short and long-term responses of the NREL 5MW wind turbine under operational conditions have been analysed using a Finite Element (FE) beam model with Winkler springs to model soil-structure interaction. It was found that as a result of scour the modal properties of the wind turbine do not change significantly. However, the maximum bending moment in the monopile increases, leading to a significant reduction in fatigue life. Backfilling the scour hole can recover the fatigue life, depending mostly on the depth after backfilling. An approximate fatigue analysis method is proposed, based on the full time-domain analysis for one scour depth, predicting with good accuracy the fatigue life for different scour depths from the quasi-static changes in the bending moment.

Keywords: OWT; Fatigue life; Scour and backfilling; Monopile, Soil-structure interaction; FE beam model; Wind energy; Renewable energy 


\section{$1 \quad 1$ Introduction}

2 Offshore wind energy is a fast-growing industry worldwide. Almost $90 \%$ of the largest offshore wind farms are located in Europe with most turbines supported on monopile foundations [1,2]. To ensure that wind energy remains competitive, it is essential to ensure that offshore wind turbines (OWT) are as cost-effective and efficient as possible. Fatigue is one of the key design driver for OWTs. The soil profile around the monopile and consequently the lateral stiffness of the structure is known to significantly influence the vibration due to environmental and rotor loads, and thus fatigue damage [3,4]. Scour changes the embedded length of the monopile and therefore the lateral stiffness of the system. A depth of $1.3 \mathrm{D}_{\text {pile }}$ (where $\mathrm{D}_{\text {pile }}$ is the diameter of the pile) was suggested as the maximum equilibrium scour depth for current-dominated regimes $[5,6]$. This value is also recommended by DNV [7] for the design of offshore monopiles. However, on-site measurements were compared with design values [8] and it was shown that a scour depth of $1.3 \mathrm{D}_{\text {pile }}$ can be conservative and that cost-savings could be achieved by adopting a lower scour level. Whitehouse et al. studied the backfilling process around monopiles using measurements from various locations in the North and Irish Seas [9]. In some cases, they reported higher scour depths than in reference [8]. A periodic variation of the scour depth depending on the time of the year was also observed, but measured data was too limited to draw firm conclusions [9]. Sørensen et al. studied the relative density of backfilling material through laboratory tests and found a range of $65 \%$ to $80 \%$ relative density with respect to the original soil [10]. Values were obtained from only one set of laboratory tests and lower densities may exist. Without scour protection, scour was found to extend laterally in the range of $4-5 D_{\text {pile. }}$ Even with scour protection, secondary scour can still occur around the pile [11].

Scour also decreases the soil resistance as it reduces the overburden pressure on the deeper soil layers $[12,13]$. Structures loaded laterally experience larger moments and displacements due to scour. Mostafa [13] studied the effects of scour width and depth on a pile loaded statically and laterally at the top. It was reported that pile head displacement and maximum bending moment increase by $155 \%$ and $200 \%$, respectively, for a large scour depth of $3 \mathrm{D}_{\text {pile. }}$ Softer soils were found to be more susceptible to scour $[14,15]$. The changes in natural frequencies of monopile-supported OWTs as a result of scour have been studied [14-18]. Various existing models of wind turbines have been investigated and the maximum reduction of the first natural frequency was up to $5 \%$ for the recommended design scour depth of $1.3 \mathrm{D}_{\text {pile. }}$. Damgaard et al. $[19,20]$ and Sørensen and Ibsen [17] studied the variations of the first natural frequency due to backfilling and found that backfilling of the scour hole recovers the modal properties of the OWT almost regardless of the backfilled material density $[17,18,20]$.

Scour affects the dynamics of OWTs at different levels. As it increases the free length of the tower/monopile, the lateral stiffness and the natural frequencies of the OWT structure decreases. The mode shapes and material soil damping change, albeit only very slightly [18]. As a result of changes in the dynamic response, the fatigue damage in the monopile is affected. Offshore wind turbines are typically designed for a minimum service life of 20 years [7,21]. Fatigue damage due to scour around a turbine in parked conditions has been studied using simulations carried out on a fully coupled model implemented in HAWC [18]. Compared to the scenario 
without scour, an increase of up to $40 \%$ in the fatigue damage was reported for scour levels of up to 1.3Dpile, kept constant throughout the turbine life. Tempel [22] studied the effects of larger levels of scour (up to $2.5 \mathrm{D}_{\text {pile }}$ ) on the fatigue damage of monopiles using a frequency-domain approach and found that this caused significant increases of up to $100 \%$ in the fatigue damage. Simple fatigue checks were conducted for various levels of scour and it was suggested that considering backfilling processes in the fatigue design of monopiles could reduce the stress demand by up to $37 \%$ [17].

In summary, scour has been shown to influence the fatigue life of offshore wind turbines and the effect of scour and backfilling on long-term damage in a parked wind turbine has been researched $[17,18,23]$. Due to the complexities associated with the fatigue analysis of offshore wind turbines, simplified methods have been proposed for this analysis [24-29]. However, the quantification of the scour influence on the fatigue life of an operational wind turbine and specific simplified methods for scour effects on fatigue analysis remain outstanding.

This paper investigates systematically the influence of scour on a reference 5MW offshore wind turbine, using FE time-domain dynamic decoupled simulations. The turbine is assumed to be in operation throughout and each scour depth investigated is considered constant throughout the OWT service life. The simulation results are combined using environmental state data to predict the actual fatigue life of the system. Full fatigue life is a key indicator for designers, but rarely calculated in the published literature. Furthermore, a novel and efficient simplified fatigue analysis method is proposed based on these findings, which might be of interest to the offshore wind industry to reduce the computational effort to account for scour effects in fatigue analyses. The methodology is described in section 2. Section 3.1 discusses the short-term effects of scour (changes in modal properties). In section 3.2, long-term effects (variation of fatigue life with scour depth and backfilling) are studied. A simplified fatigue analysis method is proposed in section 3.3, followed by conclusions in section 4 .

\section{Methodology}

\subsection{Modelling approach}

This paper investigates the fatigue life of a 5MW wind turbine model with properties provided by the US National Renewable Energy Laboratory (NREL) [30]. Various studies have been based on this wind turbine as a significant amount of data is available for it [31-37]. In this study, different software packages were used for the fatigue analysis, as shown in Fig. 1. The pre-processing module TurbSim was used to model the turbulent incoming wind field as an input to the aero-elastic software FAST [38]. FAST is a coupled aeroelastic package that provided the resultant rotor thrust time histories from the blade-wind interaction. The rotor thrust time histories were obtained from FAST, constraining the tower and monopile motion to allow for the separate modelling of aerodynamic damping. Wave load time histories were generated separately in Matlab based on the JONSWAP spectrum [40]. These were used as inputs to an FE (ABAQUS) model of the tower, monopile, and soil-structure interaction. The two separately calculated aerodynamic and wave load time histories were applied as point loads at their respective heights in the FE model, in line with previous literature. 
1 A separate ABAQUS model was developed because FAST has limited capabilities for modelling soil-structure 2 interaction and only allows for a basic structural model of the tower/monopile. Time domain dynamic analyses 3 were carried out for varying environmental conditions. FE stress time histories were rainflow-counted to 4 calculate the fatigue life of the wind turbine at every scour depth.

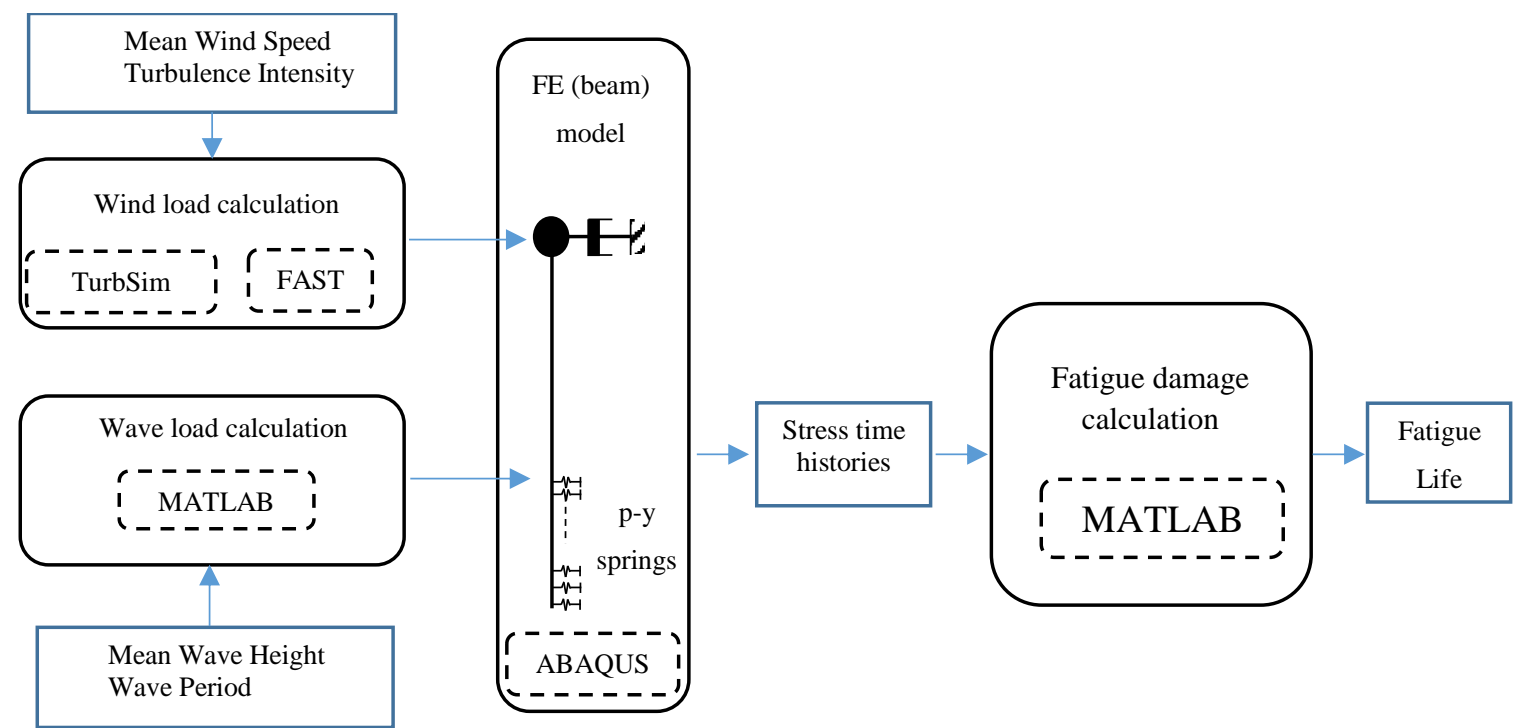

Figure 1. Schematic of software packages used in the fatigue life analysis.

\section{$5 \quad 2.2$ Geometry and properties of the OWT}

6 The NREL 5MW wind turbine is schematically shown in Fig. 2. The rotor diameter is 126m, and the hub

7 height at $92 \mathrm{~m}$ above mean sea level. The monopile embedded depth is $45 \mathrm{~m}$ and the water depth is $21 \mathrm{~m}$. The

8 steel pile section has an elastic modulus of 210GPa, a Poisson's ratio of 0.3 and a density of $7850 \mathrm{~kg} / \mathrm{m}^{3}$, while

9 a higher density $\left(\rho=8500 \mathrm{~kg} / \mathrm{m}^{3}\right)$ was used for the tower section to account for the mass of secondary steel [30].

10 The cut-in and cut-out speeds of the turbine are $3 \mathrm{~m} / \mathrm{s}$ and $25 \mathrm{~m} / \mathrm{s}$, respectively, with the rated rotor speed at

11 12.1rpm. The first natural frequency of the wind turbine is $0.25 \mathrm{~Hz}$ and lies between the $1 \mathrm{P}$ (rotor) and $3 \mathrm{P}$

12 (blade passing) frequency ranges. The rotor blades are $62.7 \mathrm{~m}$ long, with properties documented in the report

13 by Lindenburg [39]. 


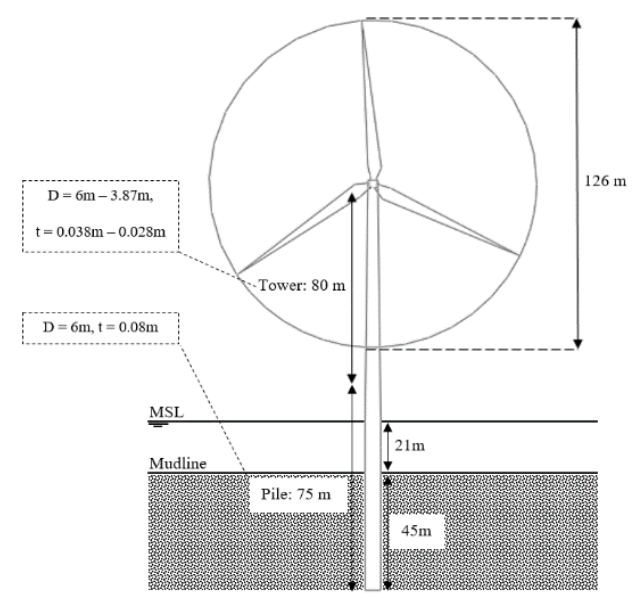

Figure 2. Reference 5MW wind turbine dimensions. D stands for the diameter of the pile or tower as per label.

\section{$1 \quad 2.3 \quad$ Numerical simulation}

2 Linear, $0.5 \mathrm{~m}$-long Timoshenko beam elements were used for the FE modelling of the tower and monopile in ABAQUS. The dynamic response of the system was studied using one-hour implicit time-domain simulations with a $0.1 \mathrm{~s}$ time increment. Four hundred seconds were added at the start of the load time series and the corresponding simulation data was later discarded to avoid any potential initial transient effects. The model included a total damping ratio of $6 \%$. This is comprised of $4 \%$ aerodynamic applied as a viscous dashpot at the tower top and $2 \%$ for combined hydrodynamic (0.2\%), structural (1\%) and soil (0.8\%) damping, applied as Rayleigh damping and calibrated using the first two bending mode natural frequencies. The hysteretic component of the soil damping is reduced slightly by scour as layers of dissipating material are removed [18]. Soil damping ratio is usually considered to be less than $1 \%$. Therefore, removing top soil for up to $10 \%$ of the embedded length of the pile can be considered to have only a negligible effect on the overall damping.

Table 1 shows the soil profile data used in this paper for the reference wind turbine at its planned location [40]. The soil profile is comprised of medium-dense to dense sands with the top layer formed from loose sand.

Table 1. Soil profile for proposed location off Netherlands coast, modified according to data from [40].

\begin{tabular}{cccc}
\hline Depth & Soil layer & $\gamma_{\mathrm{sat}}\left(\mathrm{kN} / \mathrm{m}^{3}\right)$ & $\phi^{\prime}$ \\
\hline 0m to $-15 \mathrm{~m}$ & Loose sand & 17 & 27.5 \\
$-15 \mathrm{~m}$ to $-20 \mathrm{~m}$ & Firm clay & 19 & 20 \\
$-20 \mathrm{~m}$ to $-25 \mathrm{~m}$ & Fine to medium sand & 19 & 32.5 \\
$-25 \mathrm{~m}$ to $-65 \mathrm{~m}$ & Fine to medium sand & 19 & 35 \\
\hline
\end{tabular}

The lateral support of the soil was modelled using the p-y curves recommended by DNV [7]. A spacing of $1.5 \mathrm{~m}$ was used for the soil profile discretisation (30 springs), based on results from a preliminary study (not shown). The bottom of the monopile was vertically supported on a roller due to the limited influence of vertical 
soil resistance on the lateral and bending responses of the wind turbine structure. Following a preliminary sensitivity study of the static response and dynamic properties of the wind turbine, the fairly shallow clay layer was replaced by the medium-dense sand with similar overall stiffness that lies underneath.

Local scour was modelled by removing from the soil profile, the number of top springs necessary to produce

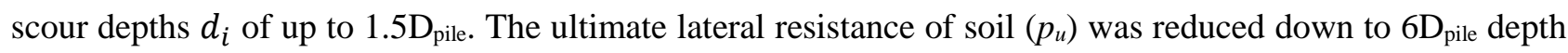
below the original seabed to include the effects of overburden pressure reduction [17]. When backfilling was investigated, springs with a p-y curve modified according to the material density and reduced angle of friction were used. A given scour depth was considered to apply for the whole life of the structure. Throughout this study, the scenario used as baseline for comparison was the design case without scour.

A set of 22 environmental states (ES) were adopted from available data for the planned location [23], as described in Table A1 (Appendix A). The wind speeds range from $4 \mathrm{~m} / \mathrm{s}$ to $24 \mathrm{~m} / \mathrm{s}$, grouped into $11 \mathrm{bins} 2 \mathrm{~m} / \mathrm{s}$ wide. Following [23], each wind speed was correlated to 2 different sea states defined as significant wave height paired with a zero-crossing period bin. The significant wave height bins were $0.5 \mathrm{~m}$ wide, ranging from $0.5 \mathrm{~m}$ to $3.0 \mathrm{~m}$, and the zero-crossing periods ranging from $3 \mathrm{~s}$ to $5 \mathrm{~s}$ were clustered into $1 \mathrm{~s}$ bins. The probability of occurrence of each sea state, also shown in Table A1 was obtained empirically from the scatter diagram presented in [23]. Wind and wave misalignment can decrease the fatigue life of OWTs by increasing the sideside vibration, which is less damped. However according to Nehal [41] the misalignment between wind and wave at this particular location is minor, so the aerodynamic and hydrodynamic loads were considered to be aligned. The Kaimal spectrum [42] was used to model wind turbulence. For the calculation of rotor thrust in FAST, a constant pitch angle corresponding to the mean wind speed considered was used, following the relationship provided by [30]. The tower, monopile and foundation flexibilities were removed to allow complete control of the aerodynamic damping in ABAQUS when the rotor thrusts were applied to the tower top [21,33]. The hydrodynamic loads from the wave and current actions were calculated using Morison's equation together with linear wave theory and Wheeler stretching for the JONSWAP spectra, commonly used for the North Sea [43]. The resultant hydrodynamic pressure was applied as a lateral force at the mean sea level. The hydrodynamic mass was added to the submerged part of the monopile, increasing the monopile density as suggested by [44]. The wind and wave loads were calculated using $0.1 \mathrm{~s}$ time increments to match the FE time steps.

\subsection{Fatigue life calculation}

The bilinear S-N curve class E, proposed by DNV [45] for the transition of weld to base material on the outside of girth welds in monopiles, was used for the calculation of fatigue damage. The parameters defining this S-N curve are shown in Table 2, where $N$ refers to the number of cycles to failure, $\log (\bar{a})$ corresponds to the intercept of the $\log (N)$ axis, $m$ is the negative inverse slope of the curve, and $S C F$ is the stress concentration factor.

Table 2. Bilinear S-N curve class E, parameters according to DNV [45]. 


\begin{tabular}{cccccc}
\hline $\mathbf{N} \leq \mathbf{1 0}^{\mathbf{6}}$ & $\mathbf{N} \geq \mathbf{1 0}^{\mathbf{6}}$ & $\begin{array}{c}\text { Thickness } \\
\text { component }\end{array}$ & Hot-spot \\
\hline $\log \left(\overline{\mathrm{a}}_{1}\right)$ & $\mathrm{m}_{1}$ & $\log \left(\overline{\mathrm{a}}_{2}\right)$ & $\mathrm{m}_{2}$ & $\mathrm{k}$ & $\mathrm{SCF}$ \\
\hline 11.61 & 3.0 & 15.35 & 5.0 & 0.2 & 1.13 \\
\hline
\end{tabular}

2 The fatigue damage was calculated along the monopile depth to consider the maximum stress at hypothetical welding points for varying scour depths. For each environmental state, the output stress time-histories from ABAQUS were rainflow counted in MATLAB and the damage calculated by adding the damages caused by each stress bin. As each environmental state has a different probability of occurrence (table A1), the total fatigue damage was obtained by summing each damage contribution according to the Palmgren-Miner (PM) sum rule.

\section{Results and discussion}

\subsection{Short-term effects of scour}

Figure 3 shows the relative changes in natural frequencies as a result of scour. The first natural frequency decreases by approximately $2.2 \%$, while the second natural frequency shows a maximum reduction of $3.6 \%$ as a result of $1.5 \mathrm{D}_{\text {pile }}$ local scour depth. The natural frequencies decrease nonlinearly with increasing scour depth for low depths and then fairly linearly for scour depths above $0.75 \mathrm{D}_{\text {pile. }}$. It should be noted that for the recommended design scour depth of $1.3 \mathrm{D}_{\text {pile, }}$ the reduction of the first natural frequency is below $2 \%$. The changes are in agreement with previous results $[22,46]$, but are too small to be reliably attributed to scour should frequency measurements be used for scour detection. The influence of scour on the mode shapes was investigated, but found to be small.

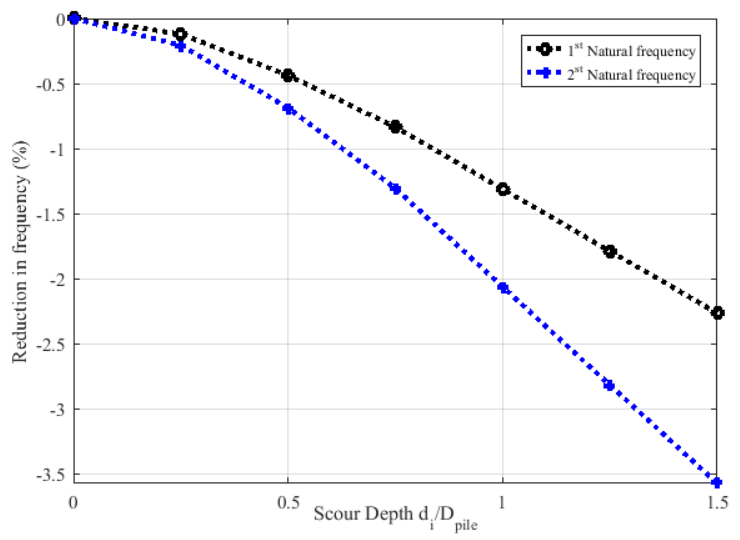

Figure 3. Relative change of natural frequencies due to scour.

Scour increases the free length of the wind turbine support structure. In monopiles, this leads to an increase in the bending moment in the structure below the seabed, which is typically the critical fatigue location for monopile-supported offshore wind turbines [28]. Figure 4(a) shows the change in bending moment in the 
monopile for a combination of $1 \mathrm{MN}$ notional static wind and wave loads. As a result of scour, the peak bending moment increases and its location shifts downwards. The maximum considered scour depth of $1.5 \mathrm{D}_{\text {pile }}$ causes an approximately $9 \%$ increase in the maximum bending moment in the monopile.

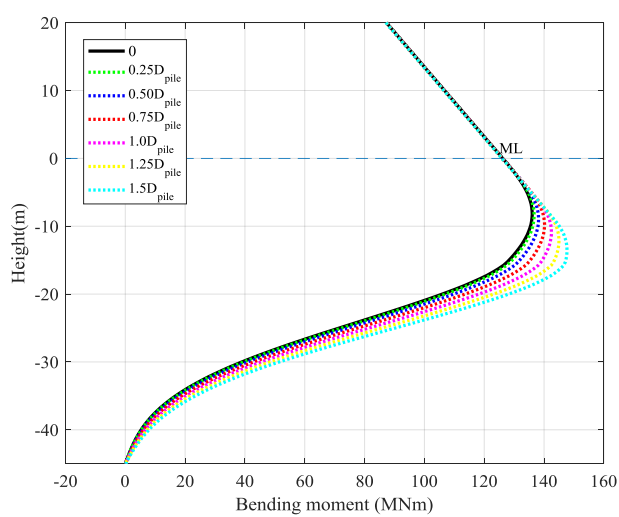

(a)

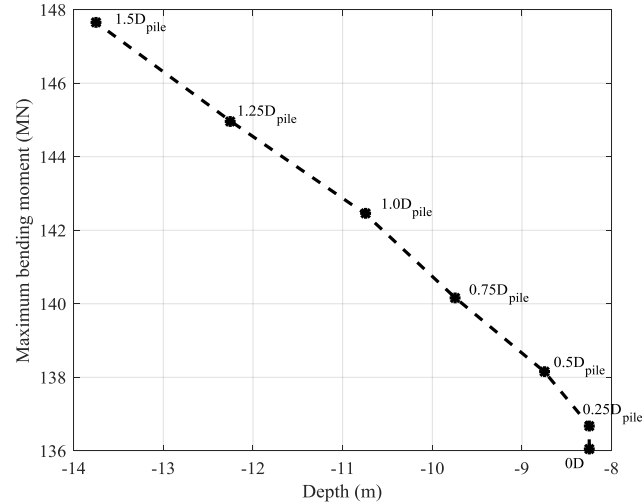

(b)

Figure 4. (a) Bending moment in the monopile (mudline is marked at zero depth) and (b) variation of maximum bending moment with its location below mudline due to varying scour depths.

Figure 4(b) shows the maximum bending moment in the monopile against its location below the mudline for varying scour depths. The location of maximum stress shifts by almost $6 \mathrm{~m}$ for a scour depth of $1.5 \mathrm{D}_{\text {pile. }}$ The location of maximum stress can also vary depending on the respective environmental load amplitudes. In the preliminary design stage, the exact weld locations in the monopile are uncertain. Because of this uncertainty, the fatigue life was calculated at three depths $\left(z_{1}=-8 \mathrm{~m}, z_{2}=-10.5 \mathrm{~m}\right.$, and $\left.z_{3}=-12 \mathrm{~m}\right)$ with high stress amplitudes, where the weld could be located. These were chosen to include the maximum bending moment for all scour depths.

\subsection{Fatigue analysis - long-term effects of scour}

\subsubsection{Environmental loads}

13 In fatigue analysis, the mean and standard deviation of the aerodynamic and hydrodynamic loads can be useful 14 to characterise their static and dynamic (varying) components. Figure 5(a) shows that the static component of the wave load increases only slightly with wave period and height, whereas the dynamic component increases significantly. Figure 5(b) shows that when the wind turbine is in operation, the mean wind load peaks at the rated wind speed and then decreases (as blades are increasingly feathered), whereas the standard deviation shows a continuous increase with the wind speed due to turbulence. As aerodynamic loads have a significantly higher lever arm from the mudline, they tend to dominate the quasi-static bending moment below mudline. 


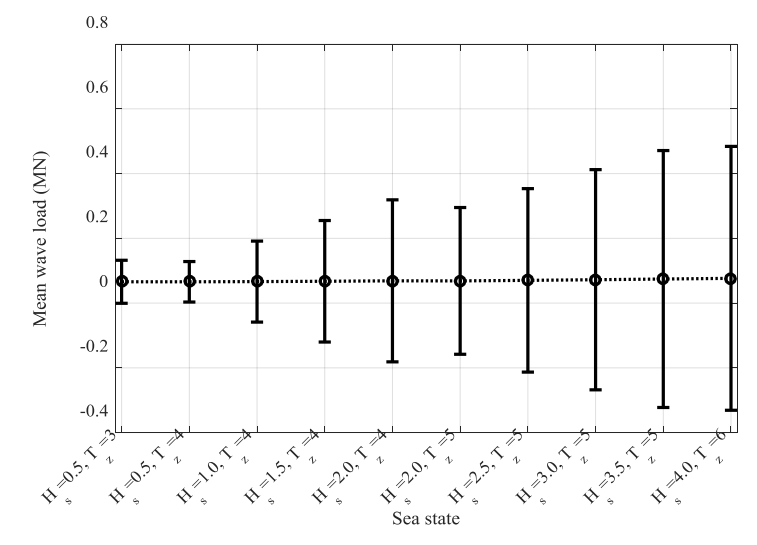

(a)

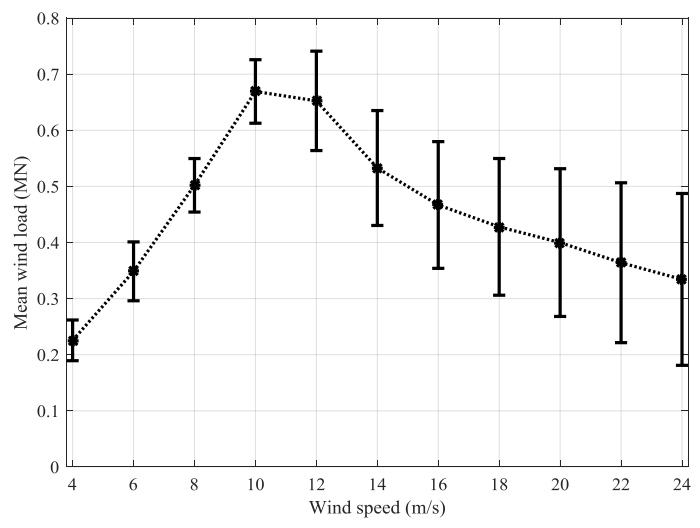

(b)

Figure 5. Mean and standard deviation of (a) wave load for different sea states and (b) wind load for varying wind speed.

\section{$2 \quad 3.2 .2$ No scour}

3 The fatigue damage in the OWT was first studied at the selected locations when no scour is present. Figure

4 6(a) shows the fatigue damage for each environmental state (section 2.3) at the three chosen depths, normalised 5 against the damage corresponding to a fatigue life of 20 years. The lower environmental states (up to \#8) lead

6 to limited fatigue damage compared to the damage caused by the higher environmental states with higher wind 7 speeds and wave heights. This mirrors the observation made from Fig. 5: as the dynamic component of the 8 loads increases, so does the fatigue damage. Small variations are observed at the considered depths, depending on the resulting bending moment of wind and wave loads and different dynamic amplification. Normalised fatigue damages at $z_{2}$ are slightly higher (by up to $\left.1 \%\right)$ than at $z_{1}$ for higher wind speeds $\left(V_{w}=18 \mathrm{~m} / \mathrm{s}\right.$, environmental states 16 and above) as the maximum bending moment for the case without scour occurs at a depth of about 8-10 meters. Figure 6(b) shows the normalised damage contribution of each environmental state, weighted by their respective probability of occurrence. The combined contribution of fatigue damage caused by the environmental states 10 to 18 accounts for more than $70 \%$ of the overall fatigue damage in the monopile. 


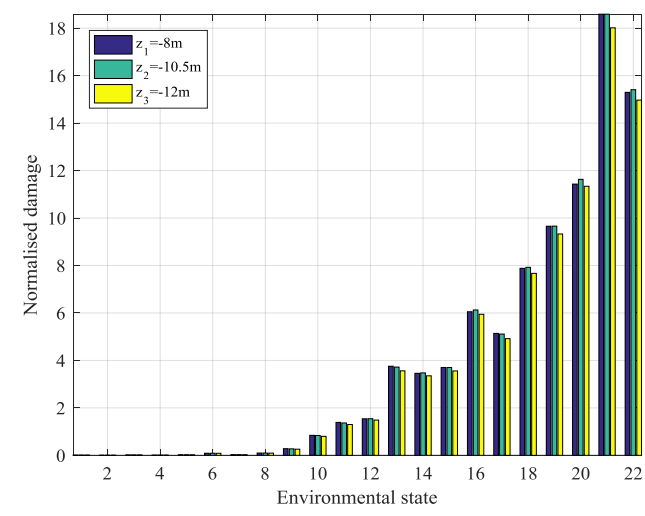

(a)

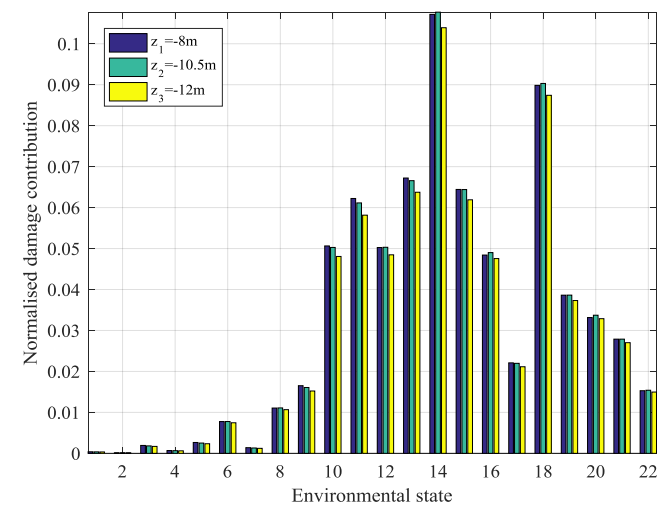

(b)

Figure 6. (a) Normalised fatigue damage and (b) normalised fatigue damage contributions of the environmental states at $z 1$ (corresponding to the maximum stress in the no scour scenario), $z_{2}$, and $z_{3}$.

1 Summing the fatigue damages from all environmental states gives a fatigue life of approximately 28 years at

2 weld location at $z_{1}=-8 \mathrm{~m}$ and at $z_{2}=-10.5 \mathrm{~m}$. The predicted fatigue life at $z_{3}=-12 \mathrm{~m}$ closer to 29 years. This

3 fatigue life result was obtained assuming no wind-wave misalignment and no idling time for wind speeds in

4 the operational range.

\section{$5 \quad 3.2 .3 \quad$ Scour with no backfilling}

6 Figure 7 shows the change in the normalised fatigue damage contribution for every environmental state due to scour depths of up to $1.5 \mathrm{D}_{\text {pile }}$ at the depth of $z_{3}=-12 \mathrm{~m}$, compared to the no scour scenario.

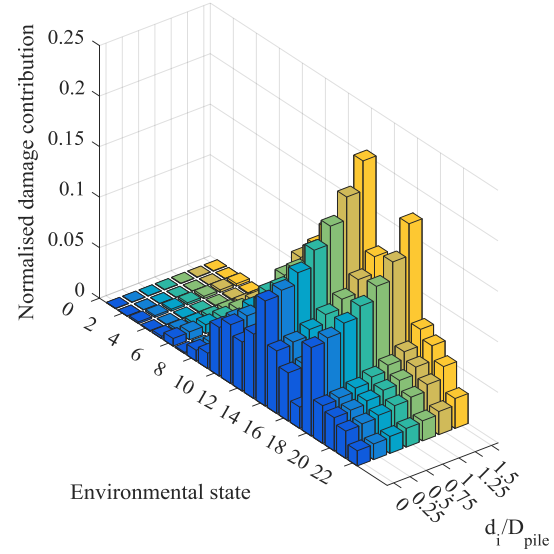

Figure 7. Comparison of the scour effects on the fatigue damage contributions of the environmental states at $z 3=-12 \mathrm{~m}$.

8 The fatigue damage contributions of each environmental state show a similar increase for scour depths of $0.25 \mathrm{D}_{\text {pile }}$ to $1.0 \mathrm{D}_{\text {pile. }}$ A higher increase is observed at $1.25 \mathrm{D}_{\text {pile }}$ and $1.5 \mathrm{D}_{\text {pile. }}$. As the location of the maximum stress shifts downwards with increased scour depth (Fig. 4b), at $z_{3}=-12 \mathrm{~m}$ a maximum increase of $102 \%$ in the normalised damage contributions is observed for a scour depth of $1.5 \mathrm{D}_{\text {pile. At }} z_{1}=-8 \mathrm{~m}$ and $z_{2}=-10.5 \mathrm{~m}$, the variations in fatigue damage contributions show a similar increase for small to moderate scour depths (up to $\left.1.0 \mathrm{D}_{\text {pile }}\right)$. However, for higher scour levels $\left(>1.0 \mathrm{D}_{\text {pile }}\right)$, a smaller increase was observed as the maximum stress 
1 is located further downwards. The largest change in the normalised fatigue damage contributions for different 2 scour depths was approximately $40 \%$ and $75 \%$ at $z_{1}=-8 \mathrm{~m}$ and $z_{2}=-10.5 \mathrm{~m}$, respectively. The combined effect 3 of the increase in bending moment and the shift in the location of maximum bending moment resulted in the 4 highest increase at $z_{3}=-12 \mathrm{~m}$ and the lowest variation at $z_{1}=-8 \mathrm{~m}$.

5 Figure 8 shows the predicted fatigue life of the wind turbine at the considered weld locations for different scour levels. The typical design life of 20 years is marked as a reference. The predicted fatigue life at $z_{l}=-8 \mathrm{~m}$, which is the critical location for the no scour scenario, reduces by $29 \%$ for a scour depth of $1.5 \mathrm{D}_{\text {pile }}$, to the design life of 20 years. However, the downward shift in the location of maximum bending moment as a result of scour leads to a higher rate of fatigue life reduction at the considered lower weld locations. At these two locations, the fatigue life reduces to below the design life for a scour depth of $1.0 \mathrm{D}_{\text {pile. }}$. At $z_{2}=-10.5 \mathrm{~m}$ and $z_{3}=$ $-12 \mathrm{~m}$, the predicted fatigue life of approximately 18 years is 2 years shorter than the design life for a scour depth of $1.25 \mathrm{D}_{\text {pile. }}$. This demonstrates how important the consideration of bending moment shift is for the fatigue limit state design of monopile-supported offshore wind turbines.

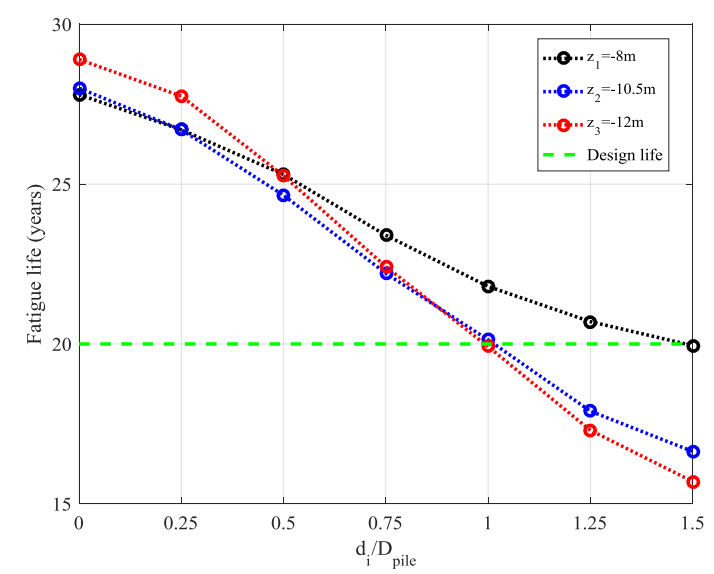

Figure 8. Fatigue life prediction for variations of scour depth around the wind turbine monopile at $z_{1}, z_{2}$ and $z_{3}$.

\subsubsection{Scour with backfilled material}

The influence of backfilling of the scour hole on the modal properties and fatigue life were investigated. The scour depth before backfilling was assumed to be $1.5 \mathrm{D}_{\text {pile }}$ and various heights and densities of the backfilled material were considered (Fig. 9). Both the reduced material stiffness related to the density and overburden pressure were accounted for in the p-y curves modelling the soil-structure interaction. 


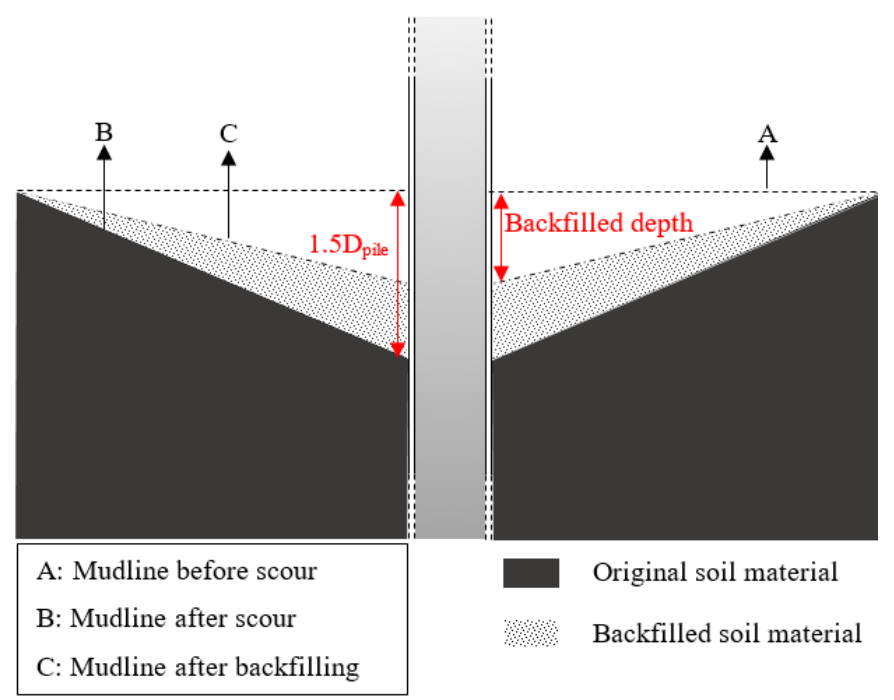

Figure 9. Diagram of the backfilling of the scour hole $\left(1.5 \mathrm{D}_{\text {pile }}\right)$ with respect to the original (zero scour) and scoured mudline levels.

1 A modal analysis of the backfilled systems showed that the density of the backfilled material has only a small 2 effect on the first natural frequency, with a maximum difference of $1 \%$ for densities as low as $20 \%$ compared 3 to the original soil. Similar observations were made in literature $[18,15]$. Figure 10 shows the predicted fatigue 4 life for backfilling of the $1.5 \mathrm{D}_{\text {pile }} \mathrm{scour}$ hole to $0.5 \mathrm{D}_{\text {pile, }}, 0.75 \mathrm{D}_{\text {pile }}$ and $1.0 \mathrm{D}_{\text {pile }}$ depths and with different backfilled material densities. The material density ratio $I_{\text {backfilled }}=100 \%$ is the reference scenario where the original soil 6 density was used for each scour depth. It can be observed that the main factor influencing the fatigue life is the 7 effective scour depth, i.e., the height of the backfill, with only smaller changes due to the material density and thus stiffness for values considered here.

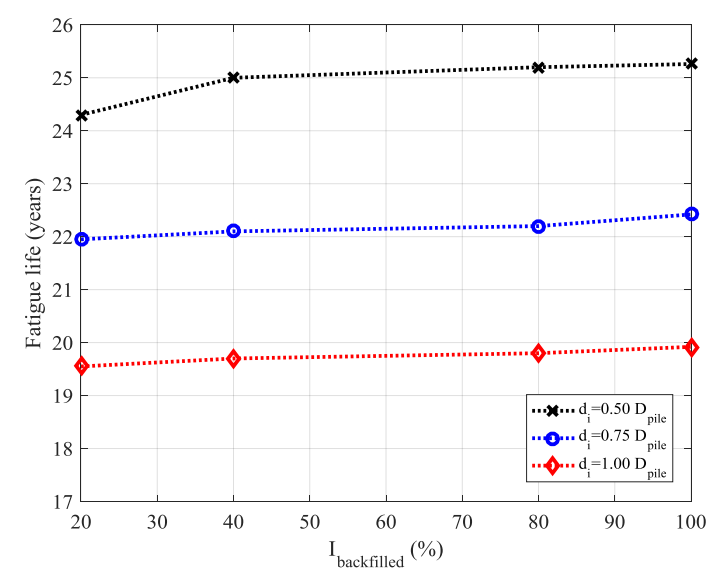

Figure 10. Fatigue life prediction for various backfill heights and material densities from a scour depth of $1.5 \mathrm{D}_{\text {pile, }}$, measured at $z 3=-12 \mathrm{~m}$.

9 The fatigue life (compared to scour with a depth of $0.5 \mathrm{D}_{\text {pile }}$ ) decreases by a maximum of one year when a $101.5 \mathrm{D}_{\text {pile }}$ scour hole is backfilled to $0.5 \mathrm{D}_{\text {pile, }}$, with a material density which is $20 \%$ ( $I_{\text {backfiled }}=20 \%$ ) of that of the 11 original material ( $I_{\text {backfilled }}=100 \%$ ), and thus the influence of backfilled material density can be regarded as very 
limited. It should be noted that for this study the top soil at the location in the North Sea was taken as loose sand (i.e. a rather soft soil), and that larger differences might be found at locations with stiffer top soils.

As discussed in section 1, scour and backfilling may occur periodically depending on the offshore conditions. As the main driver on fatigue life is the effective depth, and the dependence between the two is broadly linear (Fig. 8), the effect of backfilling can be factored in by linear interpolation of the fatigue life for different scour depths, considering the service life percentages at each depth. Another practical application of these results could be the prediction of fatigue life recovery by artificial backfilling of the scour hole after significant scour is detected. Fatigue life extension and thus economic benefits for wind energy generation can then be quantified.

\subsection{Approximate fatigue life prediction method}

In this section, a simplified fatigue analysis method is developed, allowing the effect of scour on fatigue life for a monopile-supported wind turbine in operation to be assessed with limited additional computational effort, based on the full fatigue life calculation of the system at one reference scour depth. In a design situation, this reference scour depth would probably be the maximum scour considered, but here we us the zero scour case for consistency with the previous sections. The nonlinearity of the soil springs is assumed to be small enough that the global behaviour of the system can be considered linear. For the typical frequency content of the environmental loads, the dynamic response of the structure can be considered to be well approximated by that of a single degree of freedom ( $\mathrm{SDoF}$ ) system, whose natural frequency $\omega_{1}$ and damping ratio $\zeta_{1}$ match that of the first mode of the system. The response of a linear system can be modelled as the superposition of modal responses to the wind and wave loads. As their spectral density is concentrated below the first natural frequency of the OWT system, the system vibration can be approximated reasonably well by a SDoF system with a natural frequency matched to the first mode of the OWT system. The displacement response of this SDoF system with stiffness $k$ to a harmonic force of mean $F_{m}$, amplitude $F_{a}$, and frequency $\Omega$ is given by Eq. (1), where the static and dynamic parts of the response have been labelled.

$$
u(t)=\underbrace{F_{m / k}}_{\text {Static response }}+\underbrace{\text { Quasi-static }}_{\text {Dynamic response }} \overbrace{F_{a / k}}^{\frac{1}{\text { Dynamic amplification }}},
$$

It was shown that the first natural frequency of the wind turbine changes only by a maximum of $2.2 \%$ for a scour depth of $1.5 \mathrm{D}_{\text {pile. }}$ However, the maximum bending moment in the monopile (and therefore the amplitude of the response) showed a significant difference in magnitude and location as a result of the increased free length of the structure and the changes in the stiffness of the surrounding soil. Therefore, the effect of scour on the response can primarily be attributed to the quasi-static term in Eq. (1). Accordingly, an approximate method schematically presented in Fig. 11 has been developed that uses the time-domain fatigue analysis of a 
1 reference scour case to predict efficiently the fatigue life at different scour depths. It requires the static analysis

2 of the OWT for each scour depth and the appropriate S-N curves, but no additional time-history simulation.

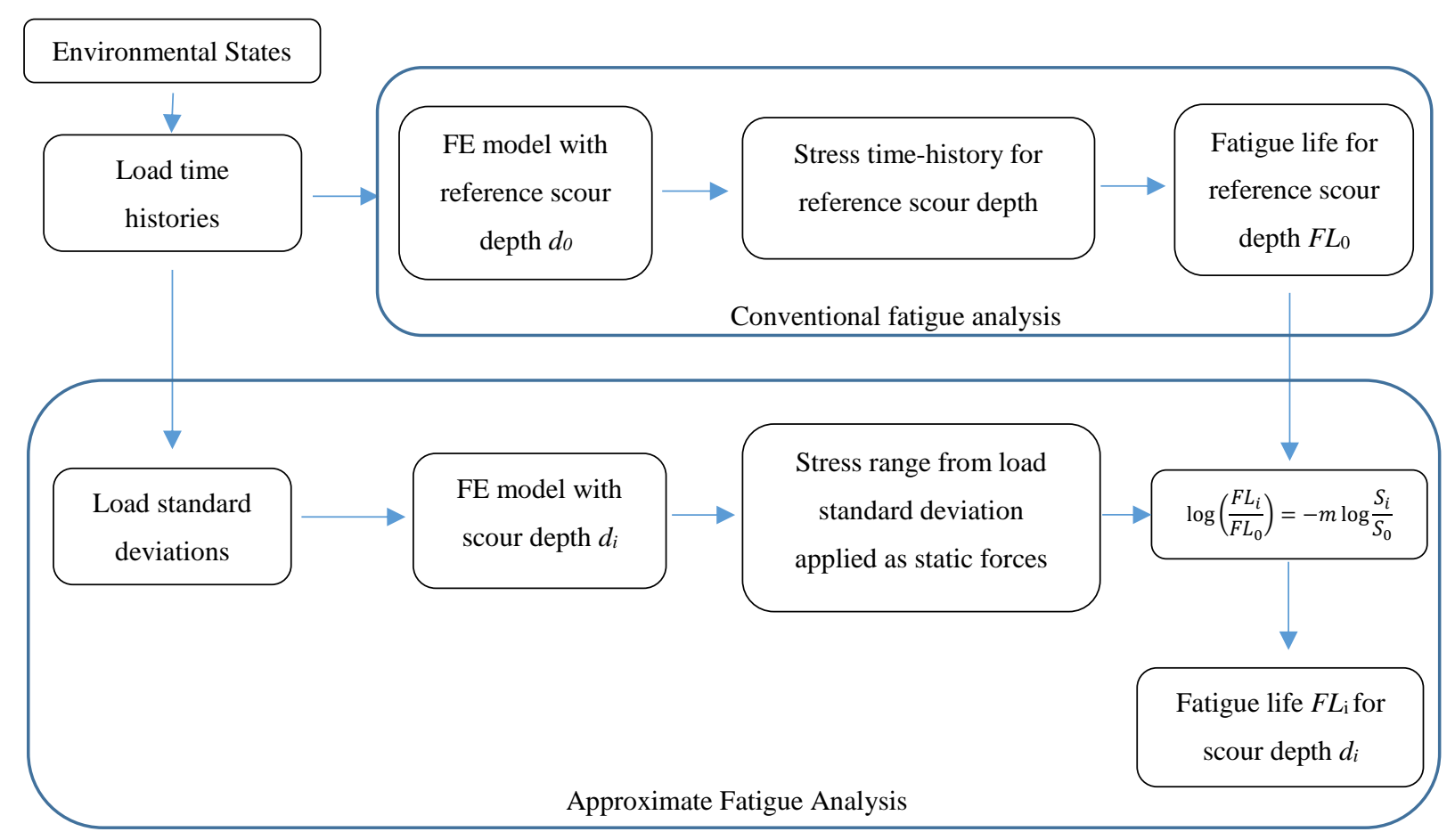

Figure 11. Schematic flow chart of the simplified fatigue analysis method to assess scour effects.

3 The approximate analysis proceeds as follows. The full fatigue life calculation requires the wind and wave load time histories for each environmental state $k$. The standard deviations of these time series are calculated and used as a proxy for the amplitude of the dynamic forces $\left(F_{\mathrm{a}}\right.$ in Eq. (1)). Applying these as static forces on the FE model of the turbine for various scour depths $d_{i}$ yields the quasi-static stress amplitude $S_{i}^{k}$. Denoting $S_{0}^{k}$ the standard deviation of the stress time history obtained for the reference scour depth (obtained the same way) and dividing $S_{i}^{k}$ by $S_{0}^{k}$ gives a stress ratio. As these ratios are slightly different for each environmental state, the weighted average of the stress ratios $\left(\overline{R_{S}}\right)$ is calculated using the probability of occurrence of each environmental state, following the damage calculation procedure.

11 In the next step, the definition of the fatigue life and S-N curves are used to express the ratio of fatigue life in 12 terms of the weighted stress ratios at different scour depths. The fatigue life $(F L)$ of the wind turbine is defined 13 by:

$$
F L=\frac{T_{\text {sim }}}{n_{s} / N_{s}},
$$

14 where $T_{\text {sim }}$ is the simulation time, $n_{s}$ is the number of stress cycles in the simulation and $N_{s}$ is the number of 15 cycles to failure for the given stress range. For two harmonic loads with the same force frequency but different 
1 magnitudes, the number of cycles in the simulation and the simulation time are the same for both stress ranges.

2 Thus, the ratio of fatigue lives $\left(F L_{i}\right)$ is given as:

$$
\log \left(\frac{F L_{2}}{F L_{1}}\right)=\log \left(\frac{N_{S 2}}{N_{S 1}}\right)=-m\left(\log S_{2}-\log S_{1}\right)=-m \log \left(\frac{S_{2}}{S_{1}}\right)=-m \log \left(\overline{R_{S}}\right),
$$

3 where $S_{1 / 2}$ are the stress ranges and $m$ is the inverse of the slope of the S-N curve. A preliminary assessment 4 of the stresses in the monopile showed that the majority of stress cycles are in the range that corresponds to 5 the part of the bi-linear S-N curve where $m=5$ (Table 2). These stress cycles also contribute to the majority of 6 the fatigue damage in the monopile. Accordingly, the slope of fatigue life and stress ratios relationship in log7 log scale was considered as a constant $m=5$ to simplify the fatigue life comparisons. Therefore Eq. (3) is 8 applicable to problems where the bulk of both stress ranges belong to the same branch of the S-N curves or 9 the cases where a linear S-N curve is assumed instead of the bi-linear S-N curve.

10 The results obtained from full fatigue analyses discussed in section 3.2 allow the validity of the approximate method and some of its underlying assumptions to be verified. Figure 12 shows the weighted stress ratios obtained as just described compared to the standard deviation of the dynamic stress ratios obtained through full time domain analyses for the same scour depths. As can be observed, both curves show a similar ascending trend with scour depth. However, the statically acquired stress ratios show a slight overestimation compared to the stress ratios obtained from the time-domain simulations, which increases with scour depth. This can be a result of fluctuations in the location of maximum bending moment in the time-domain simulations and the more pronounced role of the dynamic amplification factor, due to changes in the natural frequency, at higher scour depths. Overall this shows that the static stress ratios are a suitable substitute in fatigue damage calculation for the full dynamic stress ratios, as the maximum difference between the absolute values of the static and dynamic stress ratios is less than $2 \%$ measured at $z_{3}=-12 \mathrm{~m}$, while at $z_{1}=-8 \mathrm{~m}$, this deviation is less than $1 \%$. 


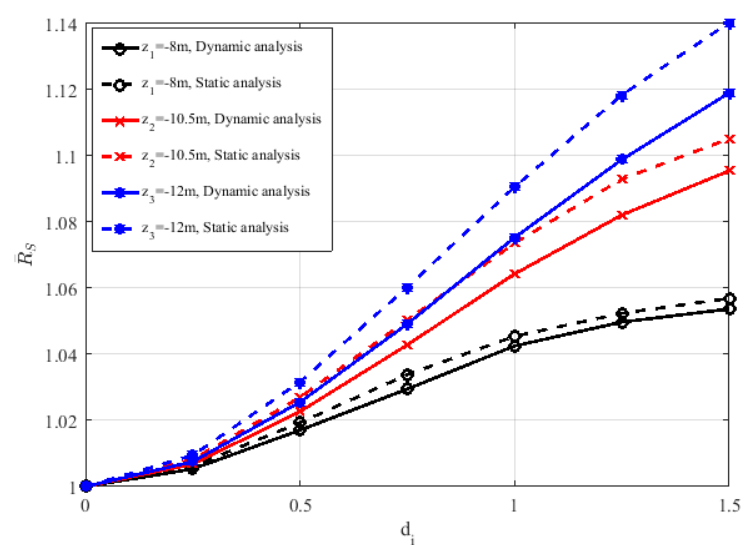

Figure 12. Comparison of the weighted average of the quasi-static stress ratios with the dynamic ratios for various scour depths at $z 1, z_{2}$ and $z 3$.

1 Figure 13 shows the relationship between the fatigue life and the weighted stress standard deviation ratios obtained from the time-domain simulations at the three locations, as an equivalent representation of the stress ratios. The dashed curve represents the analytical curve for the relationship between the fatigue life and stress ratios shown in Eq. (3). Similar to the stress ratios, the fatigue life ratios were normalised with respect to the no scour reference case. Good agreement is found between the analytical curve and the results from the timedomain simulations with a slightly increased discrepancy for scour depths of $1.25 \mathrm{D}_{\text {pile }}$ and $1.5 \mathrm{D}_{\text {pile }}$ at all three locations. This relates to the limits for the assumptions made in this study regarding the corresponding negative inverse slope $(m)$ of the section of S-N curve for which the majority of damage occurs.

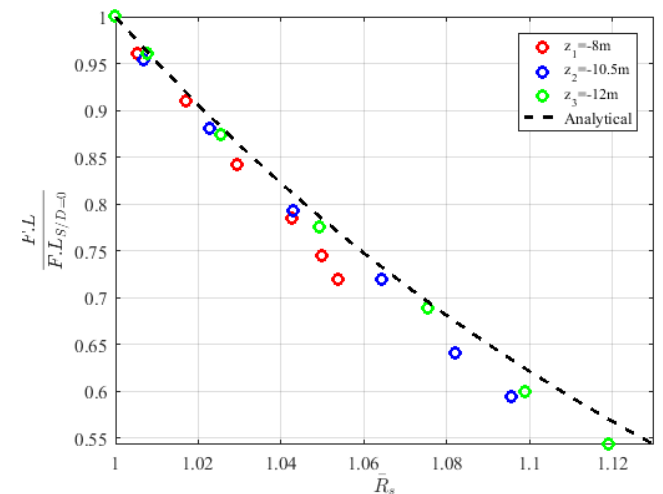

Figure 13. Changes in the fatigue life ratio with respect to the standard deviation ratio.

9 With the establishment of the close match between the static and dynamic stress response ratios, the fatigue 10 life of the wind turbine can be predicted from the analytical curve shown in Fig. 13 for different scour depths, 11 taking the respective static stress ratios into account. Figure 14 compares the fatigue life calculated by timedomain dynamic simulations with the prediction of the fatigue life from the static analysis of the wind turbine. 


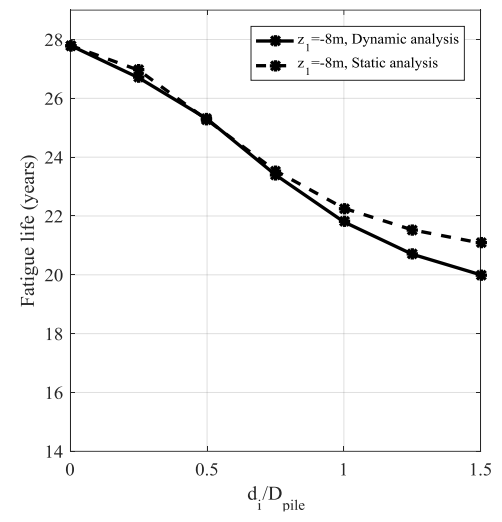

(a)

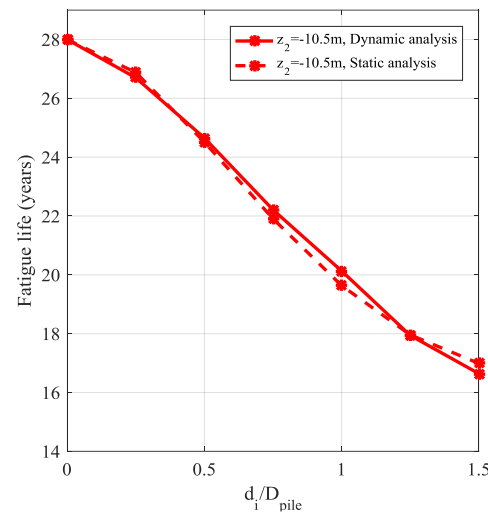

(b)

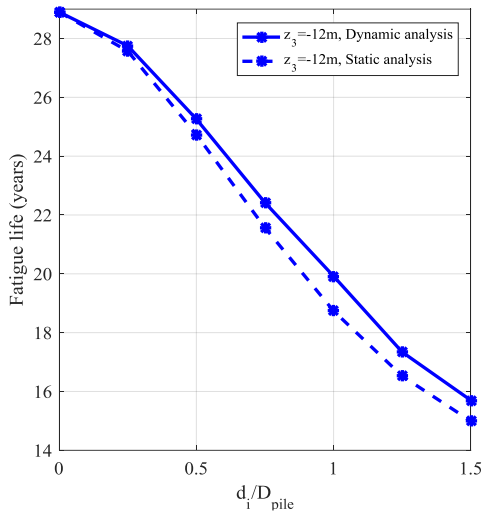

(c)

Figure 14. Comparison of fatigue life ratios between the dynamic (simulations) and static (analytical) analysis results at (a) $z_{1}=-$ $8 \mathrm{~m}$, (b) $z_{2}=-10.5 \mathrm{~m}$ and (c) $z_{3}=-12 \mathrm{~m}$.

As can be observed, good agreement exists between the two predictions, with a difference of up to 5\%. For intermediate scour depths (i.e. up to $1.0 \mathrm{D}_{\text {pile }}$ ), fatigue life ratios calculated at $z_{1}=-8 \mathrm{~m}$ and $z_{2}=-10.5 \mathrm{~m}$ show a smaller difference, while the highest differences are at $z_{3}=-12 \mathrm{~m}$. However, it should be noted that the difference between dynamic and static fatigue life ratios tend to grow with scour depth.

Consideration of scour uncertainties and backfilling process in the fatigue limit state design of offshore wind turbines is a time-consuming task. With the approximate method, the fatigue life could be examined with much less effort, using the fatigue life of the wind turbine at one scour level as a reference, and the static analysis of the wind turbine for different scour depths, provided the modal properties of the wind turbine experience only minor changes due to scour.

\section{Conclusions}

A study of the short and long-term influences of scour on fatigue life, performed using quasi-static, modal and time-domain fatigue analyses for the NREL 5MW case study wind turbine model has been presented. Modal analysis of the wind turbine support structure for various scour depths showed that the first natural frequency of the wind turbine showed limited sensitivity to scour, especially for intermediate scour levels. The static analysis showed that scour not only increases the maximum bending moment in the monopile by up to $9 \%$, but it also shifts the location of this maximum down, for instance by $6 \mathrm{~m}$ down for the maximum considered scour depth of $1.5 \mathrm{D}_{\text {pile. }}$. However, the exact shift depends on the soil profile and the relative magnitude of the loads. This phenomenon was found to be an important consequence of scour, as a variety of section details (such as welds) could be affected as the maximum bending moment shifts within this range.

To account for the uncertainty in the position of the maximum bending moment, the fatigue life was investigated at three different locations in the monopile. The fatigue analysis showed that scour influences the fatigue damage in an offshore wind turbine significantly. This study demonstrated that a scour depth of $1.5 \mathrm{D}_{\text {pile }}$ could result in a $45 \%$ reduction of the fatigue life of the wind turbine structure. This amount of change in the 
fatigue life could lead to an unsafe level for the OWT. The backfilling of the scour hole can occur naturally or can be done artificially and was shown to have a significant influence on the fatigue life. The relative material density of the backfilled soil does not have a significant effect on the modal properties or fatigue life of the wind turbine, so that the backfilled depth can be treated as an effective scour depth for simplicity in practice. The fatigue demand on the structural details reduces in direct proportion of the backfilled period. This way the cost-effectiveness of artificial backfilling and consequent fatigue life extension can be quantified.

This study showed that scour mainly influences the response of the system in a quasi-static manner, which leads to the change in the fatigue life of the wind turbine. A comparison was made between the changes in the fatigue life from the dynamic analysis of the wind turbine in the time-domain against the results from a static analysis of the wind turbine, and a good match was found. Based on this finding, an approximate fatigue analysis method was proposed, requiring one full time-domain simulation as the reference and using the statically acquired stress ratios to calculate the fatigue life. It was argued that if the changes in the natural frequency of the wind turbine are small, this approach can be applied in practice to save a significant amount of computation time in analysing the effect for different scour and backfilling scenarios. Different scenarios and costs for fatigue life extension of OWTs could be assessed for the economic benefit to further reduce renewable energy generation costs.

\section{References}

[1] J.K. Kaldellis, D. Zafirakis, The wind energy (r)evolution: A short review of a long history, Renewable Energy. 36 (2011) 1887-1901. doi:10.1016/j.renene.2011.01.002.

[2] T.Y. Liu, P.J. Tavner, Y. Feng, Y.N. Qiu, Review of recent offshore wind power developments in china, Wind Energy. 16 (2013) 786-803. doi:10.1002/we.1523.

[3] J. Sheng, S. Chen, Fatigue load simulation for foundation design of offshore wind turbines due to combined wind and wave loading, in: Proceediings 2010 World Non-Grid-Connected Wind Power Energy Conf., IEEE, Nanjing, China, 2010: pp. 1-6. doi:10.1109/WNWEC.2010.5673107.

[4] M. Mardfekri, P. Gardoni, Multi-hazard reliability assessment of offshore wind turbines, Wind Energy. 18 (2015) 1433-1450. doi:10.1002/we.1768.

[5] B.M. Sumer, J. Fredsoe, N. Christiansen, Scour around Vertical Pile in Waves, Journal of Waterway Port Coastal and Ocean Engineeringharvard. 118 (1992) 15-31.

[6] H.N.C. Breusers, G. Nicollet, H.W. Shen, Local Scour Around Cylindrical Piers, Journal of Hydraulic Research. 15 (1977) 211-252. doi:10.1080/00221687709499645.

[7] Det Norske Veritas, Design of Offshore Wind Turbine Structures, Norway, 2013.

[8] M. Høgedal, T. Hald, Scour assessment and design for scour for monopile foundations for offshore wind turbines, in: Proc. Copenhagen Offshore Wind Conf., Copenhagen, Denmark, 2005. 
1 [9] R.J.S. Whitehouse, J.M. Harris, J. Sutherland, J. Rees, The nature of scour development and scour protection at offshore windfarm foundations, Marine Pollution Bulletin. 62 (2011) 73-88. doi:10.1016/j.marpolbul.2010.09.007.

[10] S. Sørensen, L. Ibsen, P. Frigaard, Experimental evaluation of backfill in scour holes around offshore monopiles, in: Front. Offshore Geotech. II, CRC Press, 2010: pp. 617-622. doi:10.1201/b10132-84.

[11] T.U. Petersen, B. Mutlu Sumer, J. Fredsøe, T.C. Raaijmakers, J.-J. Schouten, Edge scour at scour protections around piles in the marine environment - Laboratory and field investigation, Coastal Engineering. 106 (2015) 42-72. doi:10.1016/j.coastaleng.2015.08.007.

[12] T. Camp, J. Morris, R. van Rooij, J. van der Tempel, M.B. Zaaijer, A. Henderson, K. Argyriadis, S. Schwaartz, H. Just, W. Grainger, D. Pearce, Design Methods for Offshore Wind Turbines at Exposed Sites, Delft, Netherlands, 2003.

[13] Y.E. Mostafa, Effect of Local and Global Scour on Lateral Response of Single Piles in Different Soil Conditions, Engineering. 4 (2012) 297-306. doi:10.4236/eng.2012.46039.

[14] L.J. Prendergast, D. Hester, K. Gavin, J.J. O’Sullivan, An investigation of the changes in the natural frequency of a pile affected by scour, Journal of Sound and Vibration. 332 (2013) 6685-6702. doi:10.1016/j.jsv.2013.08.020.

[15] L.J. Prendergast, K. Gavin, P. Doherty, An investigation into the effect of scour on the natural frequency of an offshore wind turbine, Ocean Engineering. 101 (2015) 1-11. doi:10.1016/j.oceaneng.2015.04.017.

[16] M. Zaaijer, J. van der Tempel, Scour protection: a necessity or a waste of money?, in: Proc. 43 IEA Topixal Expert Meet., Skaerbaek, Denmark, 2004: pp. 43-51.

[17] S.P.H. Sørensen, L.B. Ibsen, Assessment of foundation design for offshore monopiles unprotected against scour, Ocean Engineering. 63 (2013) 17-25. doi:10.1016/j.oceaneng.2013.01.016.

[18] M. Damgaard, L.V. Andersen, L.B. Ibsen, Dynamic response sensitivity of an offshore wind turbine for varying subsoil conditions, Ocean Engineering. $101 \quad$ (2015) 227-234. doi:10.1016/j.oceaneng.2015.04.039.

[19] M. Damgaard, J.K.F. Andersen, L.B. Ibsen, L.V. Andersen, Time-Varying Dynamic Properties of Offshore Wind Turbines Evaluated by Modal Testing, in: Proc. 18th Int. Conf. Soil Mech. Geotech. Eng., 2013: pp. 2343-2346.

[20] M. Damgaard, L.B. Ibsen, L.V. Andersen, J.K.F. Andersen, Cross-wind modal properties of offshore wind turbines identified by full scale testing, Journal of Wind Engineering and Industrial Aerodynamics. 116 (2013) 94-108. doi:10.1016/j.jweia.2013.03.003.

[21] IEC, Wind Turbines - Part 3: Design requirements for offshore wind turbines, Brussels, Belgium, 2009. 
1 [22] J. van der Tempel, Design of support structure for offshore wind turbines, Delft University of Technology, 2006.

[23] J. Weinert, U. Smolka, B. Schümann, P.W. Cheng, Detecting Critical Scour Developments at Monopile Foundations Under Operating Conditions, in: Proc. Eur. Wind Energy Assoc. Annu. Event, EWEA 2015, Paris, France, 2015: pp. 135-139.

[24] Y.M. Low, Extending a time/frequency domain hybrid method for riser fatigue analysis, Applied Ocean Research. 33 (2011) 79-87. doi:10.1016/j.apor.2011.02.003.

[25] J. Du, H. Li, M. Zhang, S. Wang, A novel hybrid frequency-time domain method for the fatigue damage assessment of offshore structures, Ocean Engineering. 98 (2015) 57-65. doi:10.1016/j.oceaneng.2015.02.004.

[26] V. Michalopoulos, M.B. Zaaijer, Simplified Fatigue Assessment of Offshore Wind Support Structures Accounting for Variations in a Farm, in: Proc. Eur. Wind Energy Assoc. Conf., Paris, France, 2015: pp. 1-9.

[27] B. Yeter, Y. Garbatov, C. Guedes Soares, Evaluation of fatigue damage model predictions for fixed offshore wind turbine support structures, International Journal of Fatigue. 87 (2016) 71-80. doi:10.1016/j.ijfatigue.2016.01.007.

[28] A. Iliopoulos, W. Weijtjens, D. Van Hemelrijck, C. Devriendt, Fatigue assessment of offshore wind turbines on monopile foundations using multi-band modal expansion, Wind Energy. 17 (2017) 657669. doi:10.1002/we.2104.

[29] L. Arany, S. Bhattacharya, J. Macdonald, S.J. Hogan, Simplified critical mudline bending moment spectra of offshore wind turbine support structures, Wind Energy. 18 (2015) 2171-2197. doi:10.1002/we.1812.

[30] J. Jonkman, S. Butterfield, W. Musial, G. Scott, Definition of a 5-MW reference wind turbine for offshore system development, Colorado, USA, 2009.

[31] L.I. Lago, F.L. Ponta, A.D. Otero, Analysis of alternative adaptive geometrical configurations for the NREL-5 MW wind turbine blade, Renewable Energy. 59 (2013) 13-22. doi:10.1016/j.renene.2013.03.007.

[32] C.M. Fontana, W. Carswell, S.R. Arwade, D.J. DeGroot, A.T. Myers, Sensitivity of the Dynamic Response of Monopile-Supported Offshore Wind Turbines to Structural and Foundation Damping, Wind Engineering. 39 (2015) 609-628. doi:10.1260/0309-524X.39.6.609.

[33] W. Shi, H.C. Park, C.W. Chung, H.K. Shin, S.H. Kim, S.S. Lee, C.W. Kim, Soil-structure interaction on the response of jacket-type offshore wind turbine, International Journal of Precision Engineering and Manufacturing-Green Technology. 2 (2015) 139-148. doi:10.1007/s40684-015-0018-7. 
[34] J.P. Blasques, A. Natarajan, Mean load effects on the fatigue life of offshore wind turbine monopile foundations, in: B. Brinkmann, P. Wriggers (Eds.), Proc. 5th Int. Conf. Comput. Methods Mar. Eng. Mar. 2013, International Center for Numerical Methods in Engineering (CIMNE), Hamburg, Germany, 2013: pp. 818-829.

[35] N. Alati, V. Nava, G. Failla, F. Arena, A. Santini, On the fatigue behavior of support structures for offshore wind turbines, Wind and Structures. 18 (2014) 117-134. doi:10.12989/was.2014.18.2.117.

[36] W. Shi, X. Tan, Z. Gao, T. Moan, Numerical study of ice-induced loads and responses of a monopiletype offshore wind turbine in parked and operating conditions, Cold Regions Science and Technology. 123 (2016) 121-139. doi:10.1016/j.coldregions.2015.12.007.

[37] E.A. Rendon, L. Manuel, Long-term loads for a monopile-supported offshore wind turbine, Wind Energy. 17 (2014) 209-223. doi:10.1002/we.1569.

[38] NREL, NWTC Information Portal (FAST), NREL. (2015). https://nwtc.nrel.gov/FAST (accessed March 25, 2016).

[39] C. Lindenburg, Aeroelastic Modelling of the LMH64-5 Blade, The Netherlands, 2002.

[40] R.S. Nehal, Foundation Design Monopile 3.6 \& 6.0 MW wind turbines, Amstelveen, The Netherlands, 2001.

[41] M.C. (editor) Ferguson, M. Kuhn, G.J.W. van Bussel, W.A.A.M. Bierbooms, T.T. Cockerill, B. Goransson, L.A. Harland, J.H. Vugts, R. Hes, A typical design solution for an offshore wind energy conversion, Delft, The Netherlands, 1998.

[42] J.C. Kaimal, J.C. Wyngaard, Y. Izumi, O.R. Coté, Spectral characteristics of surface-layer turbulence, Quarterly Journal of the Royal Meteorological Society. 98 (1972) 563-589. doi:10.1002/qj.49709841707.

[43] S.K. Chakrabarti, handbook of offshore engineering, first edit, Elsevier Science Ltd, Plainfield, IL, USA, 2005.

[44] A. Goyal, A.K. Chopra, Simplified Evaluation of Added Hydrodynamic Mass for Intake Towers, Journal of Engineering Mechanics. 115 (1989) 1393-1412. doi:10.1061/(ASCE)07339399(1989)115:7(1393).

[45] Det Norske Veritas, Fatigue design of offshore steel structures, Norway, 2014.

[46] M. Zaaijer, Design methods for offshore wind turbines at exposed sites (OWTES)-Sensitivity analysis for foundations of offshore wind turbines, Delft, The Netherlands, 2005. 
Table A1. Environmental states, based on data from [22].

\begin{tabular}{ccccc}
\hline State & $\begin{array}{c}\mathrm{V}_{\mathrm{W}} \\
(\mathrm{m} / \mathrm{s})\end{array}$ & $\begin{array}{c}\mathrm{T}_{\mathrm{Z}} \\
(\mathrm{s})\end{array}$ & $\begin{array}{c}\mathrm{H}_{\mathrm{S}} \\
(\mathrm{m})\end{array}$ & $\begin{array}{c}\mathrm{P}_{\text {State }} \\
(\%)\end{array}$ \\
\hline 1 & 4 & 3 & 0.5 & 3.95 \\
2 & 4 & 4 & 0.5 & 3.21 \\
3 & 6 & 3 & 0.5 & 11.17 \\
4 & 6 & 4 & 0.5 & 7.22 \\
5 & 8 & 3 & 0.5 & 11.45 \\
6 & 8 & 4 & 1.0 & 8.68 \\
7 & 10 & 3 & 0.5 & 5.31 \\
8 & 10 & 4 & 1.0 & 11.33 \\
9 & 12 & 4 & 1.0 & 5.86 \\
10 & 12 & 4 & 1.5 & 6.00 \\
11 & 14 & 4 & 1.5 & 4.48 \\
12 & 14 & 5 & 2.0 & 3.26 \\
13 & 16 & 4 & 2.0 & 1.79 \\
14 & 16 & 5 & 2.5 & 3.10 \\
15 & 18 & 5 & 2.5 & 1.74 \\
16 & 18 & 5 & 3.0 & 0.80 \\
17 & 20 & 5 & 2.5 & 0.43 \\
18 & 20 & 5 & 3.0 & 1.14 \\
19 & 22 & 5 & 3.0 & 0.40 \\
20 & 22 & 6 & 4.0 & 0.29 \\
21 & 24 & 5 & 3.5 & 0.15 \\
22 & 24 & 6 & 4.0 & 0.10 \\
\hline & & & &
\end{tabular}

3 